\title{
RHINOLOGY
}

\section{Lateral osteotomy plus hump resection vs hump re-modeling without lateral osteotomy: impact on frontal nasal view}

\author{
Confronto tra osteotomia laterale più gibbectomia e rimodellamento del gibbo \\ senza osteotomia laterale: effetti sulla visione frontale
}

\author{
P.G. GIACOMINI', A. BOCCIERI², E. FUCCILLO'1, R. DI MAURO'1, S. DI GIROLAMO'1 \\ ${ }^{1}$ Department of Clinical Sciences and Translation Medicine, Institute of Otorhinolaryngology University of Rome "Tor \\ Vergata", Italy; ${ }^{2}$ Private Practice, CdC Mercede Hospital, Rome, Italy
}

\section{SUMMARY}

This article reviews the personal experience and evolution of osteotomy approach in the last years of practice to obtain a natural appearance of the nasal pyramid in the frontal view. The aim is to analyse the long-term results after rhinoplasty on nasal width in two different cohorts of patients subjected to lateral osteotomy plus hump resection vs. hump re-modeling without lateral osteotomy considering the impact on frontal nasal view and how this relates to changes observed over time in the nasal width and contour. The study was carried out between January 2010 and December 2013, considering 42 patients undergoing primary rhinoplasty. Comparisons were made between the change in the dorsal width of the nasal pyramid at the level of the medial canthi, at the level of the inferior margin of the orbital rim, of ventral width of the nasal pyramid at the level of the medial canthi and at the level of the inferior margin of the orbital rim. In the first group, we found significant postoperative mean widening of the intercanthal dorsal width and narrowing of the ventral, while in the second group there was significant postoperative mean narrowing of the dorsal width both at level of the medial canthi and the anterior junction of the nasal bones. Our analysis seems to point out that dorsal grafting is useful for re-shaping the nasal profile with a persistent and harmonious correction of the dorsal frontal dimension of the nose. Simple hump removal/repositioning may be considered in selected instances to avoid lateral osteotomies. It also seems of paramount importance to tailor osteotomies according to nasal bone anatomy: large, strong and curved bones deserve aggressive narrowing by lateral and medial continuous osteotomies without periosteal elevation, although this approach may be insufficient to narrow the upper dorsal aspect of the nose.

KEY WORDS: Rhinoplasty $\bullet$ Nasal dorsum $\bullet$ Frontal view $\bullet$ Nasal width $\bullet$ Osteotomies

\section{RIASSUNTO}

Questo articolo presenta la nostra esperienza clinica degli ultimi anni nell'approccio alla correzione del gibbo nasale mediante il confronto tra osteotomia laterale più gibbectomia e rimodellamento del gibbo senza osteotomia laterale e valutando i risultati ottenuti nel tempo in termini di modificazione della larghezza e del contorno del dorso nasale, in visione frontale. Per la realizzazione del lavoro sono state considerate due diverse coorti di pazienti sottoposte a rinoplastica primaria, rispettivamente con o senza ricorso ad osteotomie laterali. Lo studio è stato condotto nel periodo compreso tra il 1 Gennaio 2010 ed il 31 Dicembre 2013, esaminando 42 pazienti sottoposti a rinoplastica primaria e considerando le modificazioni della larghezza dorsale della piramide nasale, misurata a livello del canto mediale ed a livello del margine inferiore del bordo orbitale e della larghezza ventrale della piramide nasale, misurata a livello del canto mediale e del margine inferiore del bordo orbitale. Nel primo gruppo di soggetti è stato osservato un significativo incremento postoperatorio della larghezza dorsale e del restringimento di quella ventrale, mentre nel secondo gruppo di pazienti è stato riscontrato un restringimento significativo della larghezza dorsale postoperatoria, misurata sia a livello del canto mediale, che della giunzione anteriore delle ossa nasali. La nostra analisi ha mostrato che il ricorso ad innesti dorsali può essere utile per una correzione persistente ed armonica del profilo nasale in visione frontale e che la rimozione semplice del gibbo sia da considerare in casi selezionati, evitando così osteotomie laterali. Il nostro lavoro ha inoltre evidenziato l'importanza delle caratteristiche anatomiche dell'osso nasale nella valutazione dell'approccio chirurgico: ossa grandi, forti e curve meritano un restringimento aggressivo con osteotomie continue laterali e mediali senza elevazione periostale, tuttavia questo approccio può essere in alcuni casi insufficiente per ridurre le dimensioni della regione superiore del dorso nasale.

PAROLE CHIAVE: Rinoplastica $・$ Dorso nasale $・$ Visione frontale $\bullet$ Larghezza nasale $\bullet$ Osteotomie 


\section{Introduction}

Rhinoplasty encompasses the aim of reshaping the nasal pyramid, and modification of the bony nasal vault is very frequently addressed to mobilise the bony pyramid for infracture, outfracture, or realignment. Osteotomies of the bony pyramid composing the upper nasal third are needed to reshape the nasal dorsum and sidewalls. Analysis of the nasal bone length and width is strategical to plan appropriate surgical measures ${ }^{12}$.

Reshaping of the bony vault may be simple, but requires both skill and experience to gain narrowing, straightening and reduction in nasal height. Various types of osteotomies have been devised to achieve this task: medial, transverse oblique, low to low lateral, low to high lateral and intermediate osteotomies. A peculiar problem is the correction of the wide pyramid: lateral osteotomies are needed for this issue ${ }^{3}$. Two basic techniques have been developed to date; the internal (endonasal) continuous technique and the external (percutaneous) perforating method, each with pros and cons ${ }^{4-9}$. A persistent problem with nasal bone osteotomies is inadequate reduction of the width of the nasal dorsum. In addition, an algorithm as to which osteotomy to use has not been fully explored ${ }^{1011}$.

This article reviews the personal experience and evolution of osteotomy approach in the last years of practice in order to obtain a natural appearance of the nasal pyramid in the frontal view. The aim is to analyse the long-term results after rhinoplasty on nasal width in two different cohorts of patients subjected to lateral osteotomy plus hump resection vs. hump re-modeling without lateral osteotomy and how this relates to the changes observed overtime in the nasal width and contour.

\section{Materials and methods}

From a series of patients subjected to rhinoplasty from January 1, 2010, through December 31, 2013, 42 unselected patients receiving primary reduction rhinoplasty were retrospectively analysed in this study. Oral and written informed consent for participation in this study was obtained from each subject.

Two different cohorts were analysed (Table I).

Group 1: treated uniformly by subperiosteal hump remov-

Table I. Characteristics of groups studied.

\begin{tabular}{lcc} 
& Group 1 & Group 2 \\
Number & 24 & 18 \\
Male/Female & $4 / 20$ & $7 / 11$ \\
Mean age \pm sd & $26.8 \pm 3.4$ & $35.1 \pm 4.7$ \\
\hline
\end{tabular}

al and paramedian + lateral osteotomy by the method of high-low-high lateral osteotomies as described by Webster et al. and Kortbus et al. ${ }^{12}{ }^{13}$ and infracture without periosteal elevation: briefly, in the presented series, we performed internal trans-vestibular, continuous, high-tolow-to-high lateral osteotomies by $3 \mathrm{~mm}$ laterally guided chisel, infracture followed, in all cases of group 1. Paramedian-oblique osteotomies were performed in 4 cases when needed for incomplete infracture obtained, a wedge excision of thick nasion bone was accomplished in 3 cases of group 1 .

Group 2: was treated by subperiosteal hump removal and remodeling-repositioning of the hump as onlay graft without lateral osteotomy. After removal of the cartilagineous-bony hump in one block by chisel, re-shaping of it was accomplished: the needed size to precisely cover the "open roof" deformity was obtained by trimming the margins, and correction of the autograft convex profile was obtained by gentle crushing of the residual bony component to flatten it to the desired shape. Repositioning of the graft via intercartilagineous incision was guided and successively secured to soft tissues of the dorsum by two (one cephalically and one caudally positioned) stitches placed in the midline of graft and dorsal skin to prevent displacement. Ultra-sharp, thin chisels and rasp were used. The follow-up ranged from 12 to 60 months (mean: $18+4$ months). Preoperative and postoperative photographs were taken with a digital camera with a 100mm Ultrasonic lens (Canon model EOS D30 camera; Canon, USA, Inc, Lake Success, NY). Flash lighting was used for all pictures. By using preoperative and postoperative photographs dimension-adjusted (interpupillary distance $=3.7 \mathrm{~mm}$ ), the postoperative dorsal width and ventral width were directly measured to the closest $\mathrm{mm}$. The preoperative photographs were rescaled to the exact size of the postoperative photographs, using the interpupillary distance as reference. Analysis of the frontal view of the nose was carried out: comparisons were made in the change in dorsal width of the nasal pyramid (d) (where the nasal bones meet each-other) at the level of the medial canthi and at the level of the inferior margin of the orbital rim, and of the ventral width of the nasal pyramid (v) (where the nasal processes of the maxilla meet the body of the maxilla) at the level of the medial canthi and at the level of the inferior margin of the orbital rim (Fig. 1). Postoperative views considered for final evaluation were taken at least 12 months after surgery and evaluations were carried out by a physician uninvolved in patient's care to avoid possible bias.

A comparison was made between groups. Statistical evaluation was carried out by computer-assisted (Microsoft- 


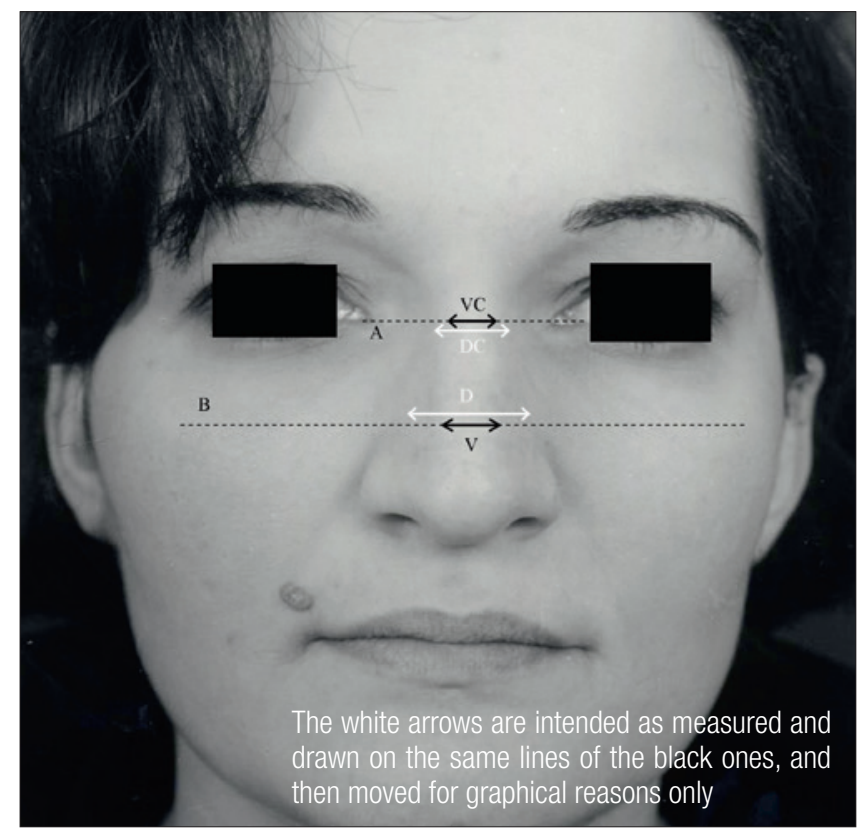

Fig. 1. Measurement of the nasal pyramid width. A) Intercanthal line level; B) inferior orbital rim level; VC) ventral intercanthal width; V) ventral infraorbital width; DC) dorsal intercanthal width; D) dorsal infraorbital width.

Excel. Usa) mean + sd comparisons by 2 -tail/paired data Student's T-test $(\mathrm{p}<0.05)$.

\section{Results}

Summary statistics of the population profile are displayed in Table I; the results of pre- and post-operative picture analysis for nasal width changes exhibited different outcomes according to groups (Tables II, III), (Figs. 2-5).

In group 1 , there was significant postoperative mean wid- ening of the intercanthal dorsal width (d) and narrowing of the ventral width (v) (where the nasal processes of the maxilla meet the body of the maxilla).

In group 2, there was significant postoperative mean narrowing of the dorsal width (d) both at level of the medial canthi and of the anterior junction of the nasal bones.

Complications linked to lateral osteotomy recorded were: one case of incomplete closure of the open roof due to insufficient reduction of the thick bone at the level of the nasion $(4.16 \%)$.

Complications linked to dorsal graft positioned recorded was one case of slight residual convexity of the dorsal profile due to its insufficient flattening during re-shaping $(5.55 \%)$.

\section{Discussion}

Osteotomy is one of the major aspects of a rhinoplasty operation. Different authors use different techniques to perform osteotomy. The external perforating approach and the internal continuous technique are the two main ways of performing osteotomy in rhinoplasty. The goals of the procedure are to: gain adequate reduction of the width of the nasal dorsum, minimise soft tissue reactions (oedema, bruising, scarring), avoid airway stenosis in the nasal valve area and obtain stable results.

A persistent problem with nasal bone osteotomies is inadequate reduction of the width of the nasal dorsum. In addition, an algorithm as to which osteotomy to use has not been fully explored ${ }^{4} 1011$.

Review of literature data in the last years seems to point out some issues: in a first attempt to quantify the amount of narrowing after nasal osteotomies, Kortbus et al. evaluated the long-term results after reduction rhinoplasty. Us-

Table II. Group 1 measurement data (M: mean, SD: standard deviation).

\begin{tabular}{ccccccccc} 
& $\begin{array}{c}\text { Pre-ventral } \\
\text { intercanthal }\end{array}$ & $\begin{array}{c}\text { Post-ventral } \\
\text { intercanthal }\end{array}$ & $\begin{array}{c}\text { Pre-dorsal } \\
\text { intercanthal }\end{array}$ & $\begin{array}{c}\text { Post-dorsal } \\
\text { intercanthal }\end{array}$ & $\begin{array}{c}\text { Pre-ventral } \\
\text { infraorbital }\end{array}$ & $\begin{array}{c}\text { Post-ventral } \\
\text { infraorbital }\end{array}$ & $\begin{array}{c}\text { Pre-dorsal } \\
\text { infraorbital }\end{array}$ & $\begin{array}{c}\text { Post-dorsal } \\
\text { infraorbital }\end{array}$ \\
M & $1.25 \mathrm{~cm}$ & $1.254167 \mathrm{~cm}$ & $0.795843 \mathrm{~cm}$ & $0.870833^{*} \mathrm{~cm}$ & $1.575 \mathrm{~cm}$ & $1.520833^{*} \mathrm{~cm}$ & 0.966667 & 0.995833 \\
$\mathrm{SD}$ & 0.90453 & 0.143746 & 0.094046 & 0.101036 & 0.213733 & 0.221008 & 0.258785 & 0.157333 \\
\hline
\end{tabular}

: statistical significance: $p<0.05$.

Table III. Group 2 measurement data (M: mean, SD: standard deviation).

\begin{tabular}{ccccccccc} 
& $\begin{array}{c}\text { Pre-ventral } \\
\text { intercanthal }\end{array}$ & $\begin{array}{c}\text { Post-ventral } \\
\text { intercanthal }\end{array}$ & $\begin{array}{c}\text { Pre-dorsal } \\
\text { intercanthal }\end{array}$ & $\begin{array}{c}\text { Post-dorsal } \\
\text { intercanthal }\end{array}$ & $\begin{array}{c}\text { Pre-ventral } \\
\text { infraorbital }\end{array}$ & $\begin{array}{c}\text { Post-ventral } \\
\text { infraorbital }\end{array}$ & $\begin{array}{c}\text { Pre-dorsal } \\
\text { infraorbital }\end{array}$ & $\begin{array}{c}\text { Post-dorsal } \\
\text { infraorbital }\end{array}$ \\
M & $1.227778 \mathrm{~cm}$ & $1.77778 \mathrm{~cm}$ & $0.844444 \mathrm{~cm}$ & $0.727778^{*} \mathrm{~cm}$ & $1.555556 \mathrm{~cm}$ & $1.511111 \mathrm{~cm}$ & $0.933333 \mathrm{~cm}$ & $0.866667^{*} \mathrm{~cm}$ \\
$\mathrm{SD}$ & 0.122758 & 0.158333 & 0.130969 & 0.13255 & 0.212786 & 0.261937 & 0.152069 & 0.206155 \\
\hline
\end{tabular}




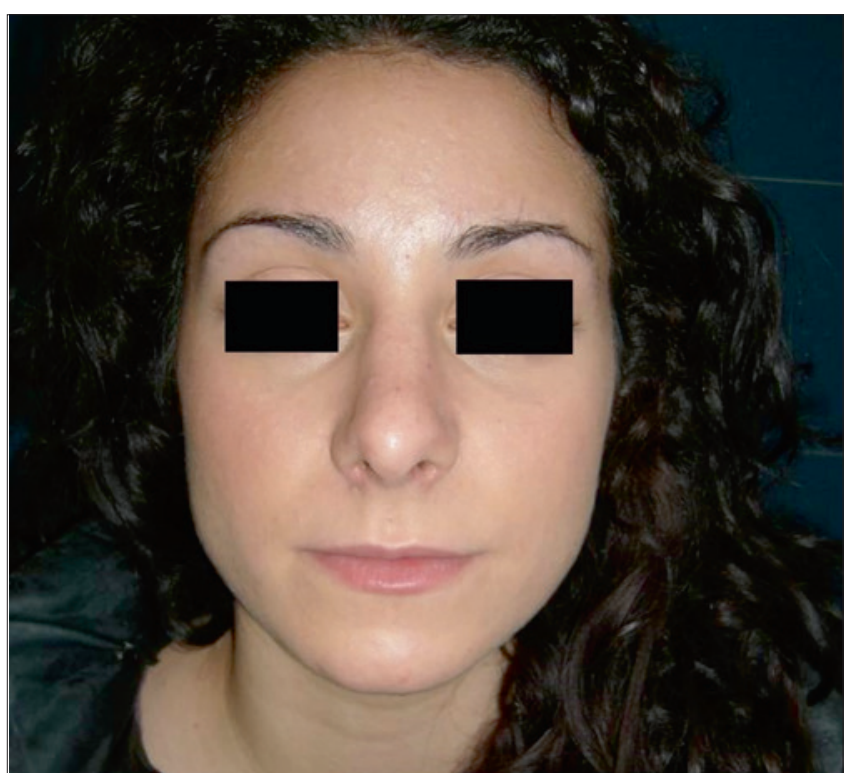

Fig. 2. Group 1 case, pre-operative picture.

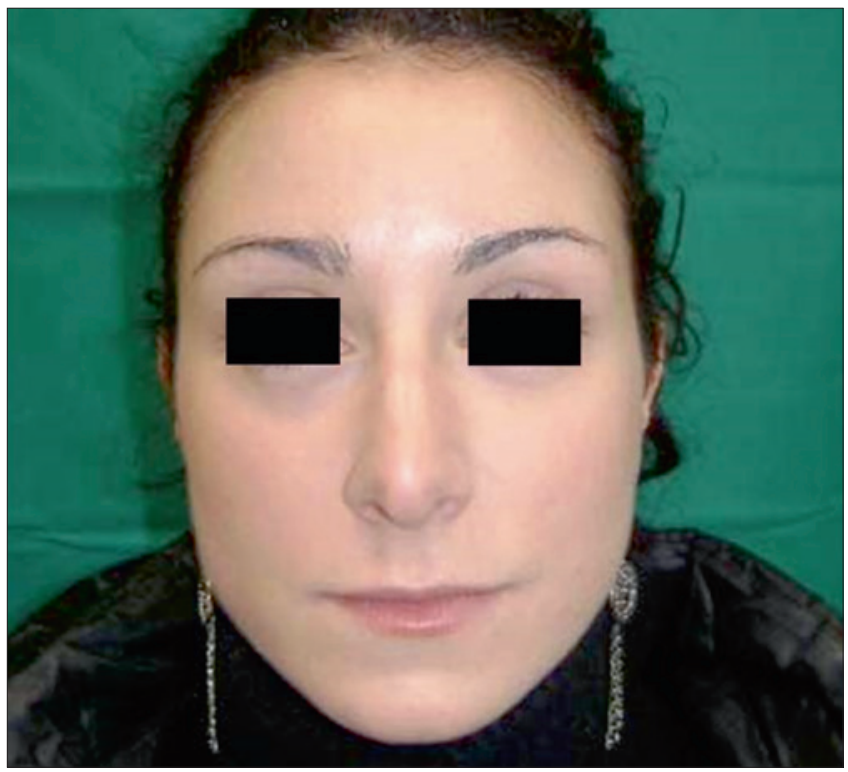

Fig. 3. Group 1 case, post-operative picture. Patient treated with subperiosteal hump removal and paramedian + lateral osteotomy.

ing preoperative and postoperative photographs, comparisons were made in the change in the dorsal width of the nose and the ventral width of the nose at the level of the middle third of the nasal pyramid in a frontal plane. A significant change in the ventral width of the nose was found after nasal bone osteotomy, but no significant change in the dorsal width of the nose. It was concluded that using

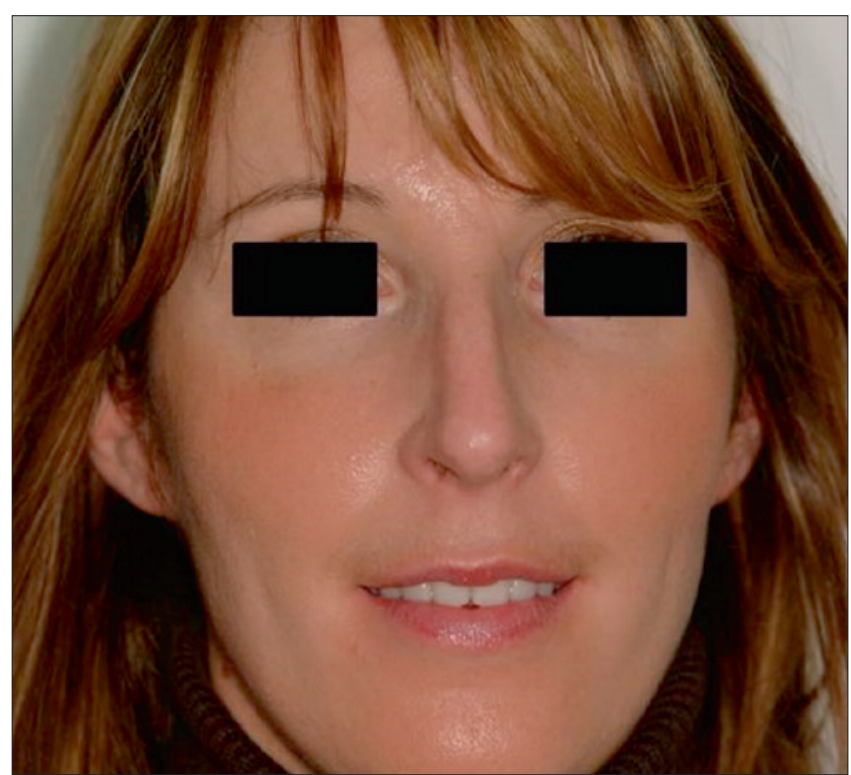

Fig. 4. Group 2 case, pre-operative picture.

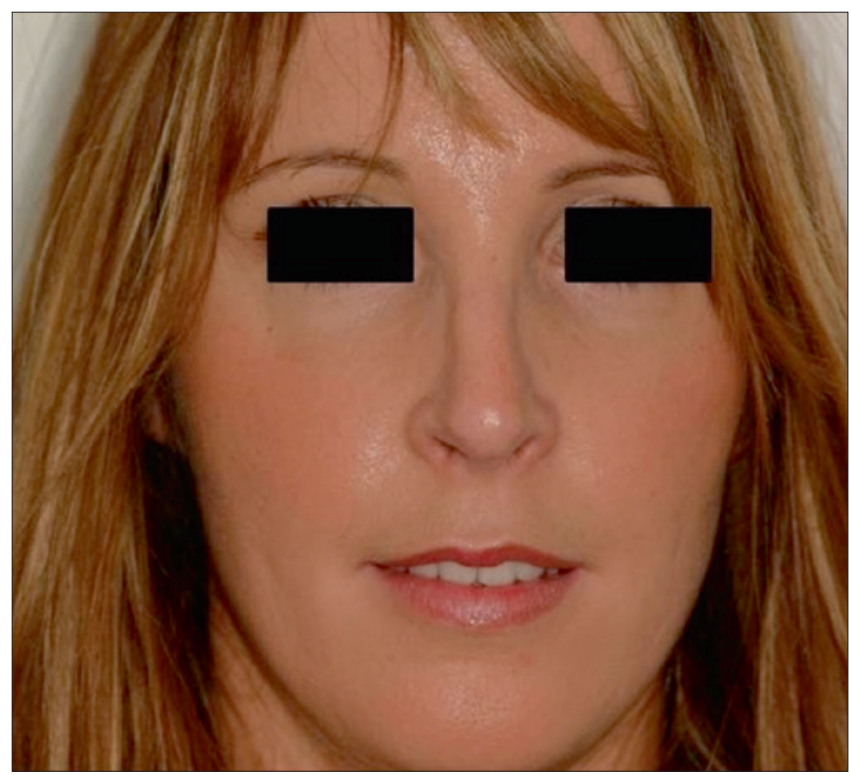

Fig. 5. Group 2 case, post-operative picture. Patient treated by subperiosteal hump-removal and remodeling-repositioning of the hump as onlay graft without lateral osteotomy.

this osteotomy, it is possible to narrow the ventral width of the nose with statistical significance. The dorsal width of the nose is maintained ${ }^{13}$.

Differently from Kortbus et al., the present paper analysed changes in nasal width at two different levels of the nasal pyramid: the upper third (intercanthal level) and the middle third (inferior orbital rim level), while both dorsal and 
ventral measurements are considered in a frontal plane. These measurements allow thorough evaluation of the upper $2 / 3$ of the nose in the frontal view. A comparison is made between cases treated by hump resection and paramedian + lateral osteotomy vs hump resection+reshaped hump onlay grafting without lateral osteotomy. At longterm, follow-up hump removal+hump grafting allows significant narrowing of the dorsal aspect of the upper $2 / 3$ of the nasal dorsum (Fig. 5). On the other hand, the use of hump resection and lateral osteotomy is effective in narrowing the ventral aspect of the middle third (in accordance with Kortbus MJ et al. results), leaving the dorsum unchanged at this level or even widened in the upper third (in around $45 \%$ of our patients). This seems to be a shared experience: Kortbus $\mathrm{MJ}$ et al. reported no changes in dorsal width after lateral osteotomy in the 20 cases analysed in that study, but noted that most surgeons counsel their patients preoperatively to mention that reducing the dorsum increases the dorsal width ${ }^{13}$.

A possible bias in our study should be taken into account: the use of paramedian + lateral osteotomies in this series was favoured in cases of excessively broad or deviated noses, whereas avoidance of lateral osteotomies was favoured in noses with straight bones. Such results seem to suggest that different goals may be achieved in correction of nasal width in the upper $2 / 3$ by selective use of different osteotomies ${ }^{10-14}$.

Gruber R. et al. (2007) tried to establish an algorithm as to which osteotomy to use: they concluded that reduction of the nasal dorsal width is facilitated by a medial oblique osteotomy alone if it is placed at the lateral aspect of the apex of the open roof. Their classification of broad nasal bones emphasises nasal width based osteotomy: type I, broad nasal base (lateral osteotomy only); type II, broad nasal base and broad dorsum (lateral and medial oblique osteotomy); and type III, broad dorsum only (medial oblique osteotomy only) ${ }^{8}$. Other authors have proposed different procedures accordingly to pyramid width ${ }^{315} 16$. In our experience, a custom-made approach to the osteotomy seems most appropriate and no single technique seems clearly useful for all situations.

A valuable adjunct to the correction of the nasal dorsum is the use of nasal bone grafts as dorsal or spreader graft, which is a safe, effective, reliable and permanent method for correction of the open roof, dorsal irregularities and crooked nose ${ }^{17}{ }^{18}$. Moreover, the onlay graft made of reshaped hump used in our (group 2) patients (without lateral osteotomies) seems to add definition to the orbitonasal lines. A better definition is therefore warranted giving the visual appearance of a narrowed nasal dorsum at postoperative evaluation and measurement, which is often missing in (group 1) cases treated by paramedian+lateral osteotomies and no grafting. We report herein one case of a complication linked to dorsal graft positioning: a slight residual convexity of the dorsal profile due to its insufficient flattening during re-shaping.

It must be taken into account that lateral nasal osteotomy is fraught with potential problems. These include nasal valve collapse, a displaced and floating or a collapsed bony segment, and nasal asymmetry. The dimensions of the nasal valve, and how it changes with osteotomies, have been measured in several studies ${ }^{1920}$. In the present series, we observed one case of incomplete closure of the open roof due to insufficient reduction of the thick bone at the level of the nasion.

It therefore seems logical to develop appropriate surgical approaches that can be employed selectively by analysing the nasal bones and determining their length and width to minimize pitfalls and maximise outcomes ${ }^{1}$.

\section{Conclusions}

The analysis of the long-term results after rhinoplasty on nasal width in two different cohorts of patients subjected to lateral osteotomy plus hump resection vs. hump re-modeling without lateral osteotomy and how this relates to the changes observed overtime in the nasal width and contour, seems to point out that dorsal grafting is useful for re-shaping the nasal width and profile with a persistent and harmonious correction of the dorsal frontal dimension of the nose. Simple hump removal/ repositioning may be considered in selected instances thus avoiding lateral osteotomies. This allows maintaining the natural narrow nasal root with good aesthetics, good function and low local morbidity (Fig. 5). It also seems of paramount importance to tailor osteotomies to nasal bone anatomy (form, thickness, consistency and previous trauma must be considered): large, strong and curved bones warrant aggressive narrowing by lateral and medial continuous osteotomies without periosteal elevation. However, this approach may be insufficient to narrow the upper dorsal aspect of the nose. Care must be taken to cut a medial bone in a laterally oriented fashion to possibly reduce the thick bone at the nasion and avoid the eventual re-widening of nasal bones. A possible bias of our study is that lateral osteotomy was not performed in straight, thin noses, but preferred in broad and/or deviated nasal pyramids

\section{Conflict of interest statement}

None declared. 


\section{References}

1 Shah AR, Constantinides M. Aligning the bony nasal vault in rhinoplasty. Facial Plast Surg 2006;22:3-8.

2 Tercan M, Yesiladali G, Ciloglu S, et al. Topographic evaluation of the medial canthus-alar groove line in terms of determining the boundaries of lateral osteotomies. Aesthetic Plast Surg 2013;37:34-8.

3 Westreich RW, Lawson W. Perforating double lateral osteotomy. Arch Facial Plast Surg 2005;7:257-60.

4 Taşkın Ü, Batmaz T, Erdil M, et al. The comparison of edema and ecchymosis after piezoelectric and conventional osteotomy in rhinoplasty. Eur Arch Otorhinolaryngol 2017;274:861-5.

5 Gruber RP, Garza RM, Cho GJ. Nasal bone osteotomies with nonpowered tools. Clin Plast Surg 2016;43:73-83.

6 Ghanaatpisheh M, Sajjadian A, Daniel RK. Superior rhinoplasty outcomes with precise nasal osteotomy: an individualized approach for maintaining function and achieving aesthetic goals. Aesthet Surg J 2015;35:28-39.

7 Robiony M, Toro C, Costa F, et al. Piezosurgery: a new method for osteotomies in rhinoplasty. J Craniofac Surg 2007;18:1098-100.

8 Yücel OT. Which type of osteotomy for edema and ecchymosis: external or internal? Ann Plast Surg 2005;55:587-90.

9 Gryskiewicz JM. Visible scars from percutaneous osteotomies. Plast Reconstr Surg 2005;116:1771-5.

10 Hontanilla B, Cabello A, Olivas J. A predictable approach for osteotomy in rhinoplasty: a new concept of open external osteotomy. Plast Reconstr Surg Glob Open 2016;4:e764.
11 Gruber R, Chang TN, Kahn D, et al. Broad nasal bone reduction: an algorithm for osteotomies. Plast Reconstr Surg 2007;119:1044-53.

12 Webster RC, Davidson TM, Smith RC. Curved lateral osteotomy for airway protection in rhinoplasty. Arch Otolaryngol 1977;103:454-8.

13 Kortbus MJ, Ham J, Fechner F. Quantitative analysis of lateral osteotomies in rhinoplasty. Arch Facial Plast Surg 2006;8:369-73.

14 Lee YH, Lee SH, Hwang K. Pentagonal hinge osteotomy for reduction of the wide nasal base of Asians. J Craniofac Surg 2012;23:1442-3.

15 Jang YJ, Wang JH, Sinha V. Percutaneous root osteotomy for correction of the deviated nose. Am J Rhinol 2007;21:515-9.

16 Cochran CS, Ducic Y, Defatta RJ. Rethinking nasal osteotomies: an anatomic approach. Laryngoscope 2007;117:662-7.

17 Quatela VC, Leake DS, Sabini P. Surgical management of concavities of the distal nose. Facial Plast Surg Clin North Am 2004;12:133-56.

18 Emsen IM. A different approach to the reconstruction of the stubborn crooked nose with a different spreader graft: nasal bone grafts harvested from the removed nasal hump. Ann Plast Surg 2009;33:674.

19 Grymer LF, Gregers-Petersen C, Baymler Pedersen H. Influence of lateral osteotomies in the dimensions of the nasal cavity. Laryngoscope 1999;109:936-8.

20 Ousterhout DK, Vargervik K, Miller AJ. Nasal airway function as it relates to the timing of mid and lower facial osteotomies. Ann Plast Surg 1983;11:175-81.

Received: August 4, 2017 - Accepted: July 8, 2018

How to cite this article: Giacomini PG, Boccieri A, Fuccillo E, et al. Lateral osteotomy plus hump resection vs hump re-modeling without lateral osteotomy: impact on frontal nasal view. Acta Otorhinolaryngol Ital 2019;39:92-97. https://doi.org/10.14639/0392$100 \mathrm{X}-1897$.

Address for correspondence: Pier Giorgio Giacomini, University of Rome "Tor Vergata", Department of Clinical Science and Translation Medicine, Institute of Otorhinolaryngology, "Tor Vergata” Hospital, via Orazio Raimondo 18, 00173 Rome, Italy. Tel. +39 0620902925 . Fax +3906 20902930. E-mail: pggiacomini@tiscali.it 